\title{
Atp6ap2/(Pro)renin Receptor Interacts with Par3 as a Cell Polarity Determinant Required for Laminar Formation during Retinal Development in Mice
}

\author{
Atsuhiro Kanda, ${ }^{1,2}$ Kousuke Noda, ${ }^{1,2}$ Kenya Yuki, ${ }^{3}$ Yoko Ozawa, ${ }^{3}$ Takahisa Furukawa, ${ }^{4}$ Atsuhiro Ichihara, ${ }^{5}$ \\ and Susumu Ishida ${ }^{1,2}$ \\ ${ }^{1}$ Laboratory of Ocular Cell Biology and Visual Science, ${ }^{2}$ Department of Ophthalmology, Hokkaido University Graduate School of Medicine, Sapporo, \\ Hokkaido 060-8638, Japan, ${ }^{3}$ Department of Ophthalmology, Keio University School of Medicine, Tokyo 160-8582, Japan, ${ }^{4}$ Laboratory for Molecular and \\ Developmental Biology, Institute for Protein Research, Osaka University, and JST, CREST, Suita, Osaka, 565-0871, Japan, and ${ }^{5}$ Department of \\ Endocrinology and Hypertension, Tokyo Women's Medical University, Tokyo 162-8666, Japan
}

(Pro)renin receptor [(P)RR], also known as Atp6ap2, has attracted growing attention as a key molecule for tissue renin-angiotensin system (RAS). In addition to its role in tissue RAS activation, Atp6ap2/(P)RR was originally identified as an accessory subunit for vacuolar $\mathrm{H}^{+}$-ATPase (v-ATPase), which is a multisubunit proton pump involved in diverse and fundamental cellular physiology. In this study, to elucidate the physiological function of Atp6ap2/(P)RR during retinal development in mammals, we used Cre-LoxP system to generate photoreceptor-specific conditional knock-out (CKO) mice, and revealed a critical role of Atp6ap2/(P)RR in photoreceptor development. Deletion of photoreceptor Atp6ap2/(P)RR did not affect retinal cell differentiation, but led to laminar disorganization around the outer nuclear layer together with severe dysfunction of photoreceptor cells. In the CKO mice, cell adhesion and polarity molecules, some of which were colocalized with Atp6ap2/(P)RR at the apical edge of the wild-type developing retina, were substantially dispersed together with mislocalization of retinal progenitor cells apart from the apical surface. Among theses molecules, coimmunoprecipitation using retinal homogenates and ATP6AP2/(P)RR-transfected cells showed that Atp6ap2/(P)RR interacted with partitioning defective 3 homolog (PAR3) protein, which is known to function in the Par-atypical protein kinase C (aPKC) system. Furthermore, yeast two-hybrid assays demonstrated direct molecular interaction between ATP6AP2/(P)RR and PAR3. Our present data revealed the novel function of Atp6ap2/ (P)RR required for laminar formation during retinal development. We propose that this cellular activity associated with the Par-aPKC system, in addition to the v-ATPase function and tissue RAS activation, is the third biological role of Atp6ap2/(P)RR.

\section{Introduction}

Six types of neurons (rod and cone photoreceptors, horizontal, bipolar, amacrine, and ganglion cells) and one type of Müller glial cell in the developing mouse retina originate from common multipotent progenitor cells in a highly conserved order, in which specific transcription-regulatory factors control cell fates (Masland, 2001; Swaroop et al., 2010). Retinal progenitor cells, initially composed of a single layer, extend processes to both apical and basal regions of the neuroepithelium. Photoreceptors

\footnotetext{
Received March 31, 2013; revised Oct. 4, 2013; accepted Nov. 4, 2013.

Author contributions: A.K. and S.I. designed research;A.K., K.N., K.Y., Y.O., T.F., and A.I. performed research;A.K., K.Y., and S.I. analyzed data; A.K. and S.I. wrote the paper.

This work was supported in part by Creation of Innovation Centers for Advanced Interdisciplinary Research Areas Program, Takeda Science Foundation, Mishima Saiichi Memorial Ophthalmic Research Japan Foundation, Suzuken Memorial Foundation, and a grant-in-aid from the Ministry of Education, Science, and Culture of Japan (to A.K., No. 24791823). We thank Ikuyo Hirose and Shiho Namba (Hokkaido University) for technical assistance, and James Friedman (University of Colorado) for technical advice on yeast two-hybrid assays.

The authors declare no competing financial interests.

Correspondence should be addressed to Dr Susumu Ishida, Department of Ophthalmology, Hokkaido University Graduate School of Medicine, N-15, W-7, Kita-ku, Sapporo, Hokkaido 060-8638, Japan. E-mail: ishidasu@med.hokudai.ac.jp.

D0I:10.1523/JNEUROSCI.1362-13.2013

Copyright $\odot 2013$ the authors $\quad 0270-6474 / 13 / 3319341-11 \$ 15.00 / 0$
}

at the apical side generate adherens junctions with Müller glial cells, and these cells are connected by cadherins at adherens junctions that play critical roles in photoreceptor cell shape and retinal tissue integrity. The partitioning defective 3 homolog (Par3)-Par6-atypical protein kinase $\mathrm{C}(\mathrm{aPKC}) \lambda$ complex (i.e., the Par-aPKC system) interacts with adherens junctions for the establishment and maintenance of cell polarity during retinal development. Genetic ablation of each of those adhesion and polarity molecules has been reported to result in severe disorganization of the retinal architecture (Horne-Badovinac et al., 2001; Wei and Malicki, 2002; Malicki et al., 2003; Masai et al., 2003; Wei et al., 2004; Koike et al., 2005).

(Pro)renin receptor $[(\mathrm{P}) \mathrm{RR}]$ is known to bind with prorenin causing the dual activation of tissue renin-angiotensin system (RAS) together with RAS-independent intracellular signaling pathways (i.e., receptor-associated prorenin system), and contributes to the molecular pathogenesis of end-organ damage, such as inflammation and angiogenesis (Kanda et al., 2012; Satofuka et al., 2012). Initially, (P)RR was found as a truncated form of (P)RR at the C-terminal region associated with vacuolar $\mathrm{H}^{+}$-ATPase (v-ATPase), an ATPdependent multisubunit proton pump, and termed ATP6 accessory protein 2 (Atp6ap2; Ludwig et al., 1998; Nguyen et al., 2002). The $\mathrm{v}$-ATPase is involved in various fundamental and physiological cel- 
lular activities including endocytosis, processing of proteins and signaling molecules, membrane sorting and trafficking, activation of lysosomal and autophagosomal enzymes, and left-right patterning during development (Nishi and Forgac, 2002; Adams et al., 2006). Recently, Atp6ap2/(P)RR and v-ATPase-mediated acidification were shown to be essential for both of the Wnt/ $\beta$-catenin and Wnt/ planar cell polarity signaling pathways in Xenopus and Drosophila (Buechling et al., 2010; Cruciat et al., 2010; Hermle et al., 2010). Cardiomyocyte- or podocyte-specific gene ablation in mice revealed that Atp6ap2 is essential for the maintenance of cell structure and survival (Kinouchi et al., 2010; Oshima et al., 2011; Riediger et al., 2011). Therefore, Atp6ap2/(P)RR is suggested to contribute not only to tissue RAS activation but to multiple biological processes via the $\mathrm{v}$-ATPase function.

We recently reported that ATP6AP2/(P)RR is associated with angiogenic activity in human eyes with diabetic retinopathy (Kanda et al., 2012, 2013); however, no functional analysis has ever been reported on the physiological role of ATP6AP2/(P)RR in mammalian eyes. In the present study, we generated conditional knock-out (CKO) mice for photoreceptor-specific disruption of the Atp6ap2/(P)RR gene, and investigated its biological functions in retinal development. We herein report the first evidence that shows the close association between Atp6ap2/(P)RR and retinal lamination together with molecular mechanisms related to the Par-aPKC system.

\section{Materials and Methods}

Photoreceptor-specific Atp6ap2-CKO mice. Atp6ap2-floxed mice (Kinouchi et al., 2010) were bred with a cone-rod homeobox (Crx)-Cre transgenic mouse line (Nishida et al., 2003), which expresses Cre recombinase under the control of the photoreceptor-specific Crx promoter. All animal experiments were conducted in accordance with the Association for Research in Vision and Ophthalmology Statement for the Use of Animals in Ophthalmic and Vision Research, and were approved by the Ethics Review Committee for Animal Experimentation of Hokkaido University.

Immunofluorescence microscopy. Mouse eyeballs were fixed in $4 \%$ paraformaldehyde for $30 \mathrm{~min}$ on ice, incubated in an increasing concentration of PBS/sucrose (10, 20, 30\%), and embedded in Frozen Section Compound (Leica). For antibody staining, sections were washed with PBS containing $0.05 \%$ Triton X-100, and then blocked in PBS containing $0.05 \%$ Triton X-100 and 5\% goat serum. Sections were probed with the following primary antibodies: mouse and rabbit anti-Atp6ap2 (1:50, Kanda et al., 2012; and 1:100, Sigma-Aldrich), mouse anti-rhodopsin (1:500, Millipore), rabbit anti-cone arrestin (1:100, Millipore), rabbit anti-calbindin (1:100, Millipore), mouse anti-glutamine synthetase (1:200, Millipore), rabbit anti-Par3 (1:100, Millipore), rabbit antiphosphorylated (p)-histone H3 (1:200, Millipore), mouse anti-Pax6 (1:50, Developmental Studies Hybridoma Bank), goat anti-Brn3 (1:50, Santa Cruz Biotechnology) and rabbit anti-Par6 (1:100, Santa Cruz Biotechnology), sheep anti-Chx10 (1:50, Abcam), chicken anti-calreticulin (1:100, Abcam) and mouse anti-58K Golgi protein (1:50, Abcam), mouse anti-N-cadherin (1:100, BD Biosciences), mouse anti- $\beta$-catenin ( $1: 100, \mathrm{BD}$ Biosciences) and mouse anti-aPKC $\lambda$ (1:100, BD Biosciences), rabbit anti-zona occludens (ZO)-1 (1:250, Life Technologies), rabbit anti-Crb2 (1:100, Thermo Scientific), rabbit anti-Pals1 (1:100, Proteintech), and mouse anti- $\alpha$-tubulin (1: 200, Sigma-Aldrich) antibodies. The secondary antibodies for fluorescent detection were Alexa Fluor 488 and 546 (1:500, Life Technologies) and HiLyte Fluor 647 (1:500; AnaSpec). Sections were visualized under a FluoView 1000 confocal microscope (Olympus).

Reverse transcription PCR analyses for Atp6ap2 in mouse retinas. Total RNA was isolated from retinas using TRIzol (Life Technologies). Reverse transcription was performed with GoScrip Reverse Transcriptase (Promega) and oligo dT(20) primers, as previously described (Kanda et al., 2012). PCR analyses were performed with the following primers for mouse genes: Atp6ap2; forward 5' -CTG GTG GCG GGT GCT TTA G-3', reverse $5^{\prime}$-GCT ACG TCT GGG ATT CGA TCT-3' and Actb; forward
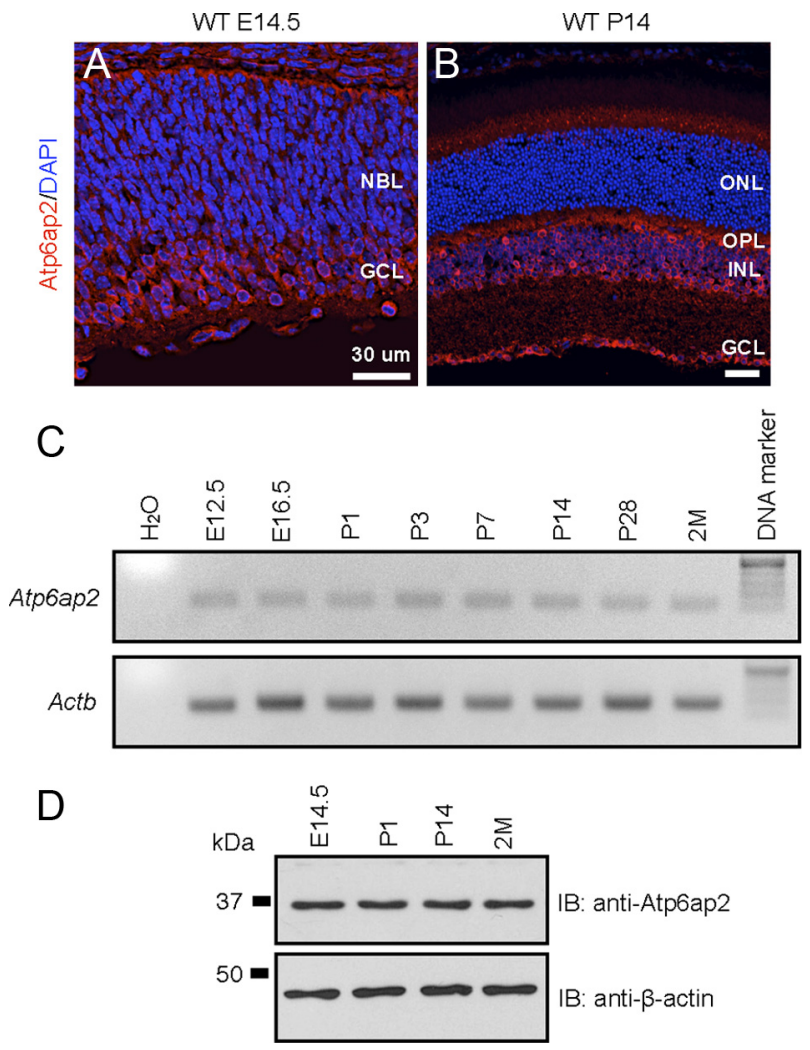

Figure 1. Retinal localization and expression of Atp6ap2 in wild-type mice. $\boldsymbol{A}, \boldsymbol{B}$, Atp6ap2 immunostaining of the retina at E14.5 $(\boldsymbol{A})$ and P14 $(\boldsymbol{B})$. NBL, Neuroblastic layer; ONL, outer nuclear layer; $\mathrm{OPL}$, outer plexiform layer; INL, inner nuclear layer; $\mathrm{GCL}$, ganglion cell layer. Scale bar, $30 \mu \mathrm{m}$. C, Gene expression analysis of Atp6ap2 during mouse retinal development. $\boldsymbol{D}$, Immunoblot analysis of Atp6ap2 during mouse retinal development.

\section{5'-CAT CCG TAA AGA CCT CTA TGC CAA C-3', reverse 5' -ATG GAG CCA CCG ATC CAC A-3'.}

Cell counting of retinal cell types. For quantitative analysis of retinal cells, postnatal day $(\mathrm{P}) 14$ retina were dissected in DMEM, cut into small pieces, and dissociated by continuous mixing in DMEM containing tryp$\sin$ at $37^{\circ} \mathrm{C}$ for $15 \mathrm{~min}$. Dissociated cells were fixed for $10 \mathrm{~min}$ at room temperature, then for $20 \mathrm{~min}$ at $37^{\circ} \mathrm{C}$ in $4 \%$ paraformaldehyde in PBS. Immunostaining was performed as described above with the respective retinal marker antibodies. Four independent experiments in triplicate were performed to count the number of each type of retinal cells.

$E R G$. Electroretinography (ERG) recordings were performed as described previously (Yuki et al., 2011). In brief, male mice at the age of 4 weeks were dark-adapted overnight, and then anesthetized with an intramuscular injection of $70 \mathrm{mg} / \mathrm{kg}$ pentobarbital sodium and the pupils were dilated with a mixed solution of $0.5 \%$ tropicamide and $0.5 \%$ phenylephrine (Mydrin-P, Santen) just before light exposure. Single-flash ERG responses were recorded with the active contact-lens electrodes (Mayo) placed on the cornea (PowerLab system 2/25; AD Instruments). Light pulses of $800 \mathrm{~cd} \cdot \mathrm{s} / \mathrm{m}^{2}$ with $4 \mathrm{~ms}$ duration were delivered via a commercial Ganzfeld stimulator (Ganzfeld System SG-2002, LKC Technologies). Amplitudes were measured from baseline to the a-wave trough for a-waves and from the a-wave trough to the b-wave peak for b-waves.

Plasmid construction and mutagenesis. Human ATP6AP2 cDNA (GenBank No. NM_005765) was subcloned in the pCI vector with FLAG-tag (Promega). All deletion mutants from the ATP6AP2 expression construct were generated by PCR. Human PAR3 cDNA (GenBank NM_001184785) was subcloned in the pCMV-Tag 3B vector with Myc-tag (Agilent Technologies). All constructs were sequence-verified before use.

Coimmunoprecipitation and immunoblot analyses. HEK293T cells were transiently transfected with plasmid DNA using FuGENE HD (Promega). Mouse retinas or the transfected cells were homogenized in a radioimmunoprecipitation assay (RIPA) buffer containing protease inhibitors 

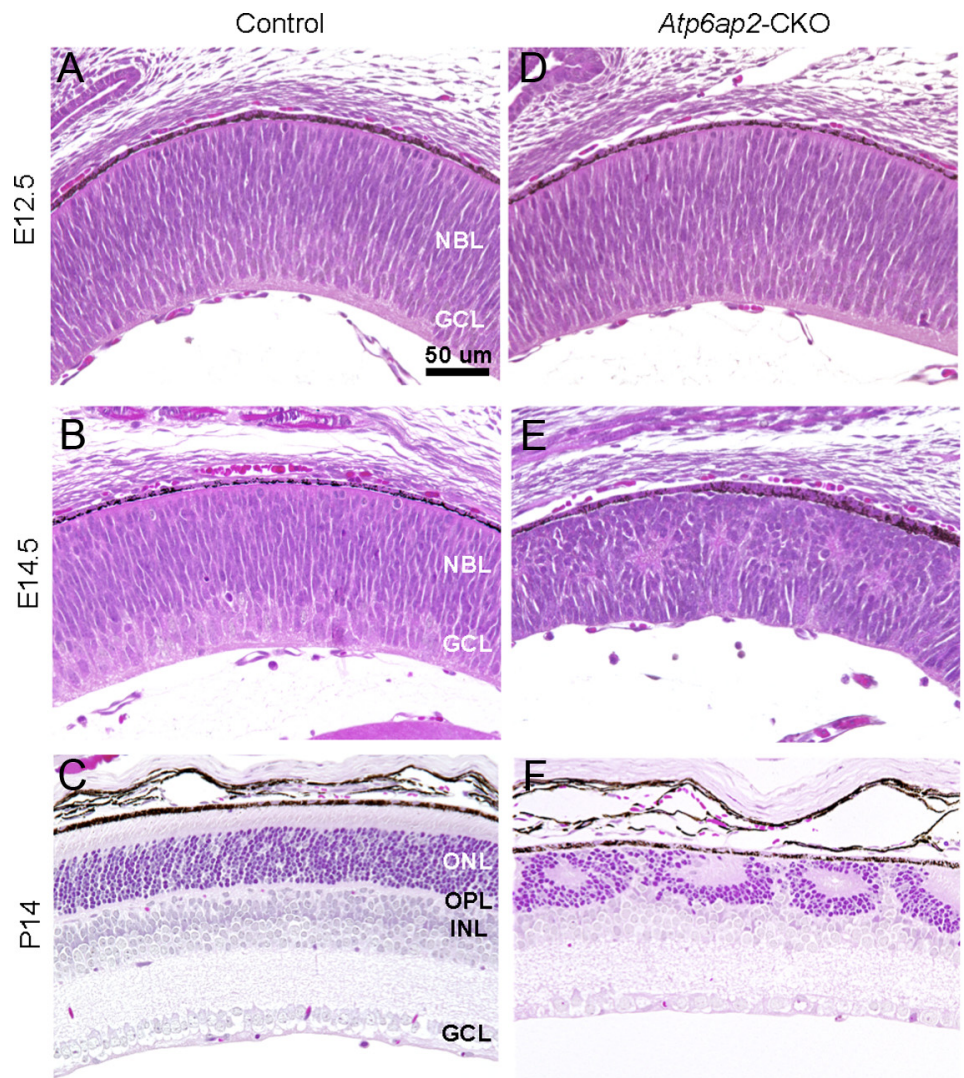

G

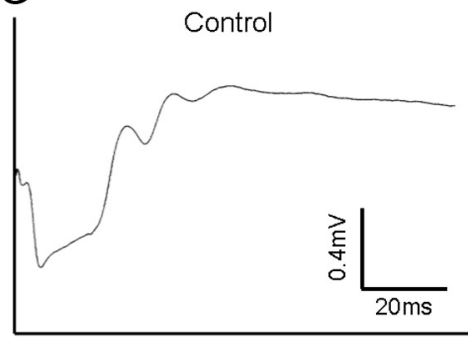

$\mathrm{H}$
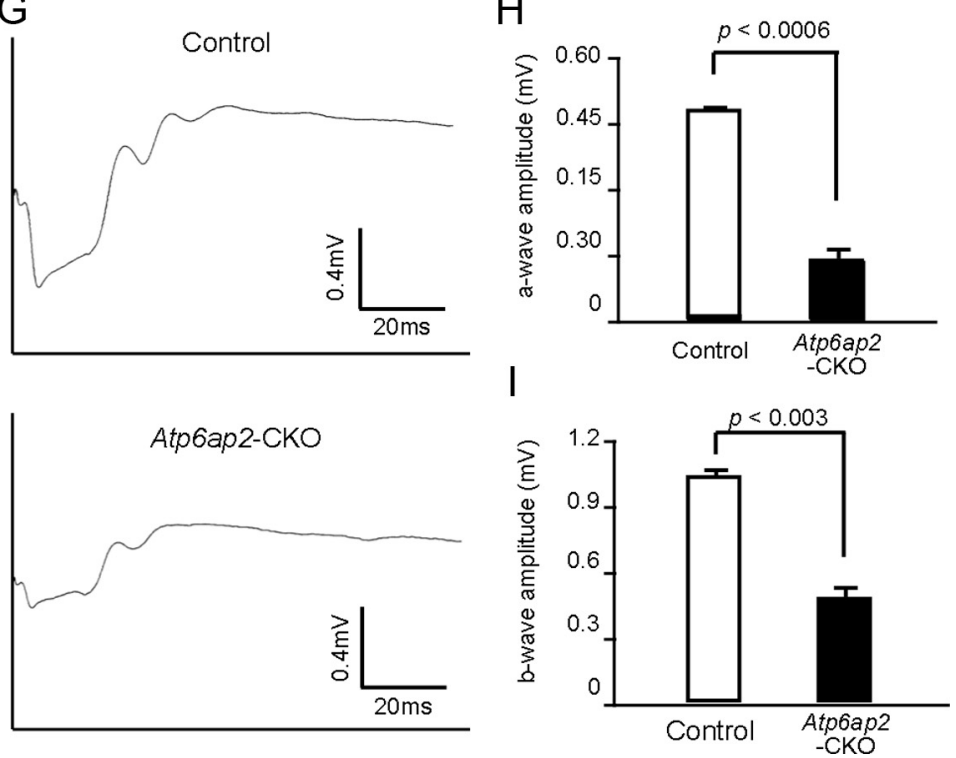

Figure 2. Retinal structure and function were damaged in Atp6ap2-CKO mice. A-F, H\&E staining of control and Atp6ap2-CKO retinas at E12.5, 14.5, and P14. NBL, Neuroblastic layer; ONL, outer nuclear layer; OPL, outer plexiform layer; INL, inner nuclear layer; GCL, ganglion cell layer. Scale bar, $50 \mu \mathrm{m}$. G-I, Full-field ERG. Representative wave responses from 4-week-old control and CKO mice $(\boldsymbol{G})$. Significant difference was observed in the a-wave amplitude $(\boldsymbol{H})$ and $b$-wave amplitude $(\boldsymbol{I})$ between control and Atp6ap2-CK0 mice. Control mice, $n=6$; Atp6ap2-CKO mice, $n=7$.

(Roche Applied Science). After preincubation of sonicated extracts with Protein $\mathrm{G}$ beads (Life Technologies), antibodies were added and left overnight at $4^{\circ} \mathrm{C}$ with gentle mixing. The beads were washed with the RIPA buffer, suspended in SDS sample buffer, and separated by SDS-PAGE. Proteins were transferred to polyvinylidene fluoride membrane by electroblotting, and immunoblot analyses were performed as previously described (Kanda et al., 2012). Antibodies for protein analysis were anti-FLAG and Myc (1:1000, Wako Pure Chemical Industries).
Known-bait and known-prey yeast twohybrid analyses. Known-bait and known-prey analyses were performed using the Matchmaker Gal4 two-hybrid system, according to the manufacturer's instruction (Clontech). ATP6AP2 and PAR3 were alternately subcloned into either the bait vector pGBKT7 or the prey vector pGADT7 (Clontech). Yeast AH109 cells were transformed sequentially with the bait and prey vectors. Transformants were selected for the bait [minus-tryptophan $(T R P)$ selection] and prey [minus-leucine (LEU) selection] vectors. Yeast AH109 cells containing the bait and prey vectors grew in nutrition selection plates [minus-TRP, -LEU, -histidine (HIS), and -adenosine (ADE) selection] with lac $Z$ gene expression in blue by filter lift assay for $\beta$-galactosidase activity.

Statistical analyses. All results were expressed as mean \pm SEM. The values were processed for statistical analyses (Student's $t$ test). Differences were considered statistically significant when the $p$ values were $<0.05$.

\section{Results}

Retinal localization and expression of Atp6ap2 in wild-type mice

Atp6ap2 has been reported to localize on the inner segment, the ganglion cell layer and the inner nuclear layer (within Müller cells) in the retina of adult mice (Kanda et al., 2012); however, no study on its retinal localization at early time points during embryonic development has ever been reported. To investigate Atp6ap2 protein localization on the embryonic retina, we performed immunofluorescence in the retina of wild-type (WT) mice. Atp6ap2 signals were observed abundantly, and relatively stronger at the apical edge of the neuroblastic layer and the ganglion cell layer at embryonic day (E)14.5 retinas (Fig. 1A). Atp6ap2 staining at P14 retinas (Fig. $1 B$ ) was consistent with our previous report (Kanda et al., 2012).

To elucidate retinal expression of Atp6ap2 during normal development, we performed semiquantitative PCR experiments using retinal RNA from E12.5 to 2-month-old WT mice (Fig. 1C). The Atp6ар2 transcript was detected at E12.5, and expression levels were not altered remarkably until 2 months of age. Immunoblot analysis also showed similar results with the semiquantitative PCR experiments, and Atp6ap2 protein levels were stable during retinal development (Fig. 1D). These results suggest that Atp6ap2 is required for development and maintenance of the mouse retina.

\section{Retinal structure and function were damaged in Atp6ap2- CKO mice}

To understand biological functions of Atp6ap2 in photoreceptor cells, we generated CKO mice for photoreceptor-specific disruption of Atp6ap2 by crossing loxP/Atp6ap2 mice and cone-rod homeobox (Crx)-Cre transgenic mice. Crx-Cre begins to be expressed at E12.5 

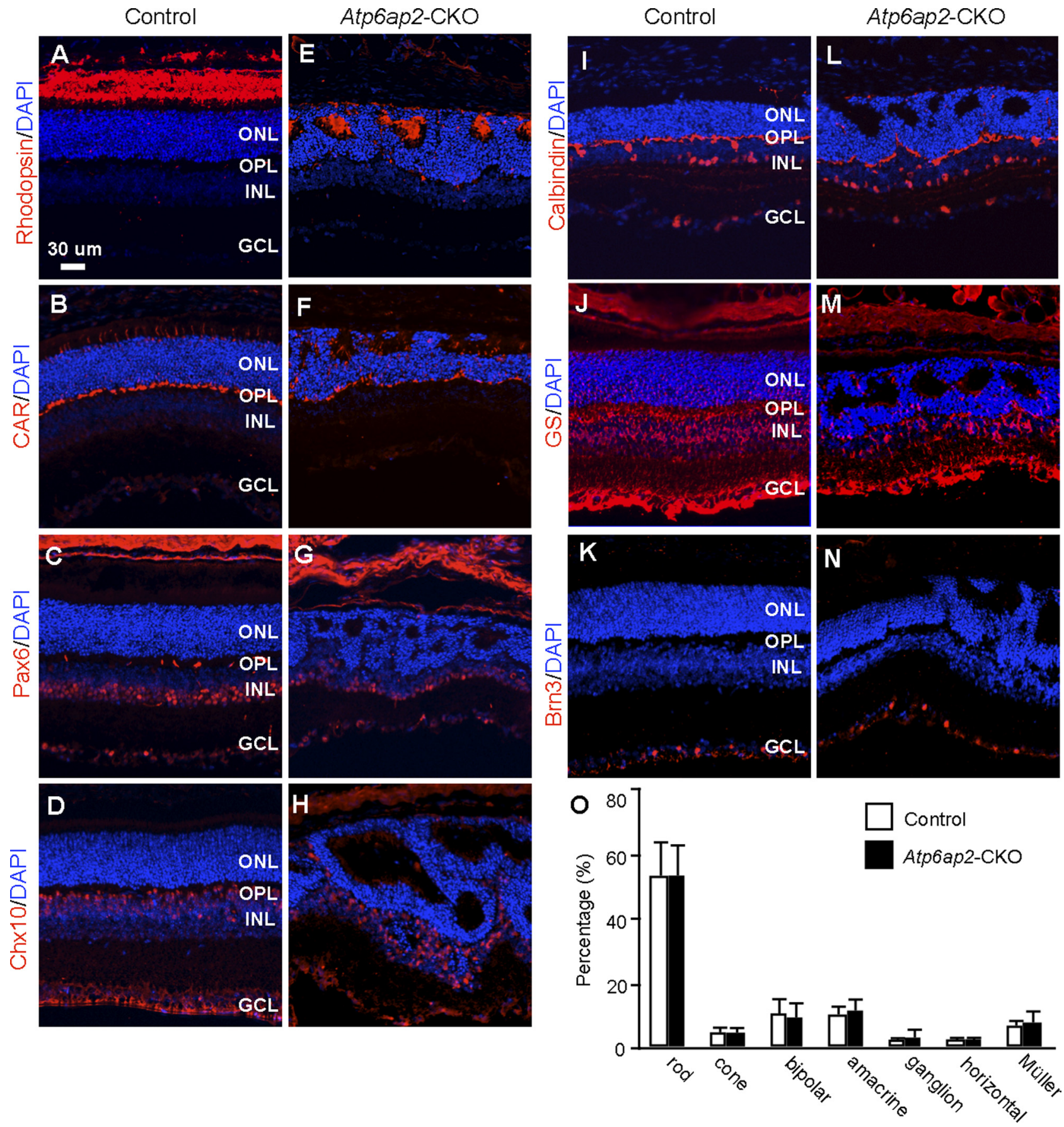

Figure 3. Loss of Atp6ap2 in photoreceptor cells did not affect cell fate determination. Sections of control $(\boldsymbol{A}-\boldsymbol{D}, \boldsymbol{I}-\boldsymbol{K})$ or Atp6ap2-CKO $(\boldsymbol{E}-\boldsymbol{H}, \boldsymbol{L}-\boldsymbol{N})$ retinas at P14 were stained with antibodies against individual retinal cell-type markers (red) and counter-stained with DAPI (blue). Rod photoreceptor, rhodopsin $(\boldsymbol{A}, \boldsymbol{E})$; cone photoreceptor, cone arrestin (CAR; $\boldsymbol{B}, \boldsymbol{F})$; amacrine and ganglion cells, Pax6 (C, G); bipolar cells, Chx10 (D, H); horizontal cells, calbindin $(\boldsymbol{I}, \boldsymbol{L})$; Müller cells, glutamine sysnthetase (GS; J, $\boldsymbol{M})$; ganglion cells, Brn3 $(\boldsymbol{K}, \boldsymbol{N})$. ONL, Outer nuclear layer; OPL, outer plexiform layer; INL, inner nuclear layer; GCL, ganglion cell layer. Scale bar, $30 \mu \mathrm{m}$. $\mathbf{0}$, The percentage of cell types in control and Atp6ap2-CKO retinas.

in the outer neuroblastic layer of the embryo where the precursors of photoreceptor cells are located (Nishida et al., 2003; Koike et al., 2005). As for the floxed mice, we used the previously established loxP/Atp6ap2 mice (Kinouchi et al., 2010). The resultant observations of the CKO (Atp6ap2 $\left.2^{l o x / Y} / \mathrm{Crx}-\mathrm{Cr}^{+}\right)$retina in this study were based on Atp6ap2 deficiency from an early developmental stage. Their littermates (e.g., Atp6ap2 $2^{\operatorname{lox} / Y} / \mathrm{Crx}-\mathrm{Cre}^{-/-}$) served as control mice.

We first analyzed the cellular structure of Atp6ap2-CKO retinas at E12.5, E14.5, and P14. The control retina showed retinal laminar structure and fully developed at P14 (Fig. 2A-C). No obvious difference between control and CKO retinas was found at E12.5 (Fig. 2D); however, the CKO mice at E14.5 exhibited retinal thinning and cellular defects (Fig. 2E), and retinal lamination was remarkably disrupted with plexiform patches and sporadic rosette-like structures in the outer nuclear layer were observed at P14 (Fig. 2F).

To investigate the functional loss in the CKO retina, we recorded the dark-adapted ERG responses. Importantly, the amplitude of the CKO mice was significantly reduced compared with 

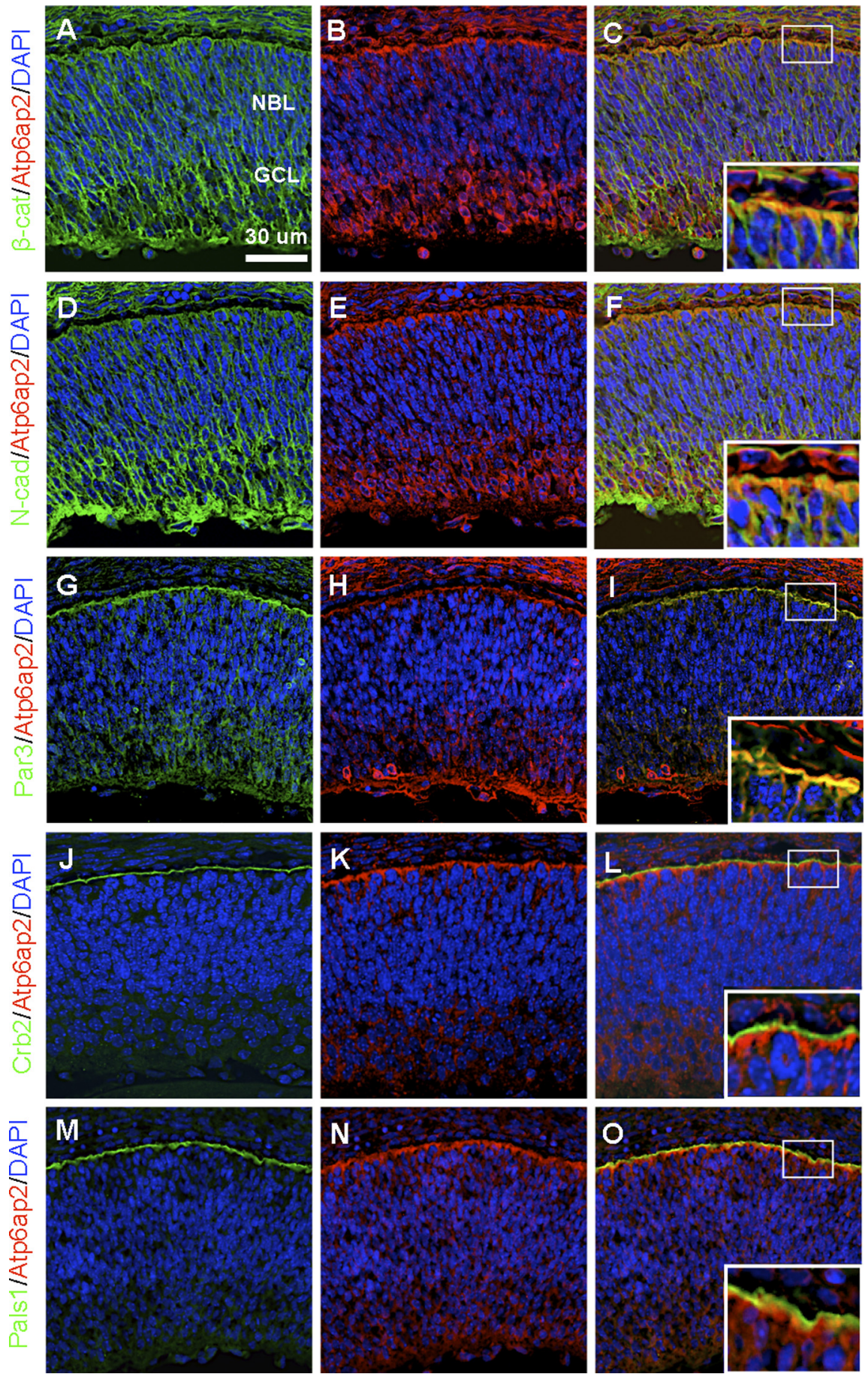

Figure 4. Colocalization of Atp6ap2 with cell adhesion and polarity molecules in the developing retina. $A-C$, Double-labeling of $\beta$-catenin ( $\beta$-cat, green) and Atp6ap2 (red) and DAPI (blue). $\boldsymbol{D}-\boldsymbol{F}$, Double-labeling of $\mathrm{N}$-cadherin ( $\mathrm{N}$-cad, green) and Atp6ap2 (red) and DAPI (blue). G-I, Double-labeling of Par3 (green) and Atp6ap2 (red) and DAPI (blue). J-L, Double-labeling of Crb2 (green) and Atp6ap2 (red) and DAPI (blue). $\mathbf{M - 0}$, Double-labeling of Pals1 (green) and Atp6ap2 (red) and DAPI (blue). Inserted images show higher-magnification. NBL, Neuroblastic layer; GCL, ganglion cell layer. Scale bar, $30 \mu \mathrm{m}$. retinal sections from control and $\mathrm{CKO}$ mice at P14, using antibodies against retinal cell type markers (Fig. $3 A-N$ ). The CKO retina (Fig. $3 E-H, L-N$ ) contained all types of retinal cells including rod photoreceptor cells (antirhodopsin antibody), cone photoreceptor cells (anticone arrestin antibody), amacrine and ganglion cells (anti-Pax6 antibody), bipolar cells (anti-Chx10 antibody), horizontal cells (anticalbindin antibody), Müller glial cells (anti-glutamine synthetase antibody), and ganglion cells (anti-Brn3 antibody). Quantification of the different cell types in the whole retinal population revealed no significant proportional change in any of the cell types (Fig. 30). These results demonstrate that Atp6ap2 deficiency in photoreceptor cells did not affect the normal specification and cell fate determination of retinal cell types.

Colocalization of Atp6ap2 with cell adhesion and polarity molecules in the developing retina

Several molecules controlling cell adhesion and cell polarity, such as $\beta$-catenin, $\mathrm{N}$-cadherin, Par3, Crumbs (Crb) 2, and protein associated with Lin Seven 1 (Pals1), have been reported to play crucial roles in physiological development, and deletion of any of those in the retina demonstrated the loss of the radial arrangement of retinal progenitor cells (Wei and Malicki, 2002; Erdmann et al., 2003; Malicki et al., 2003; Masai et al., 2003; Wei et al., 2004; Fu et al., 2006; Omori and Malicki, 2006). Because disruption of Atp6ap 2 in photoreceptors also led to lamination defects in the photoreceptor layer, we studied the localization and expression of $\beta$ catenin, N-cadherin, Par3, Crb2, and Pals 1 in the developing retina. In WT retinas at E14.5, the immunofluorescent signals of those molecules were detected ubiquitously in various retinal cells, and relatively stronger at the apical and basal surfaces (Fig. $4 A, D, G, J, M$ ), consistent with previous findings (Koike et al., 2005; Fu et al., 2006; Cho et al., 2012). Interestingly, Atp6ap2 immunoreactivity was colocalized with $\beta$-catenin, $\mathrm{N}$-cadherin, and Par3, but not Crb2 or Pals1, signals at the apical surface (Fig. $4 B, C, E, F, H, I, K, L, N, O$ ). that of control mice (a-wave, $p<0.0006$; b-wave, $p<0.003$; Fig. $2 G-I)$. These results indicate that photoreceptor Atp6ap2 plays a significant role in retinal function.

\section{Loss of Atp6ap2 in photoreceptor cells did not affect cell} fate determination

To determine whether Atp6ap2 deficiency in photoreceptors affects cell fate determination, we performed immunostaining for
Loss of Atp6ap2 in photoreceptor cells led to mislocalization of cell adhesion and polarity molecules

To investigate whether loss of Atp6ap2 in photoreceptor cells affects cell adhesion and polarity molecules, retinal localization of those proteins in the CKO mice were analyzed (Figs. 5, 6).

The Crb-Pals1-Patj (Pals1-associated tight junction protein) complex plays a key role in regulating cell polarity and cell shape (Omori and Malicki, 2006; Bulgakova and Knust, 2009; Zou et al., 

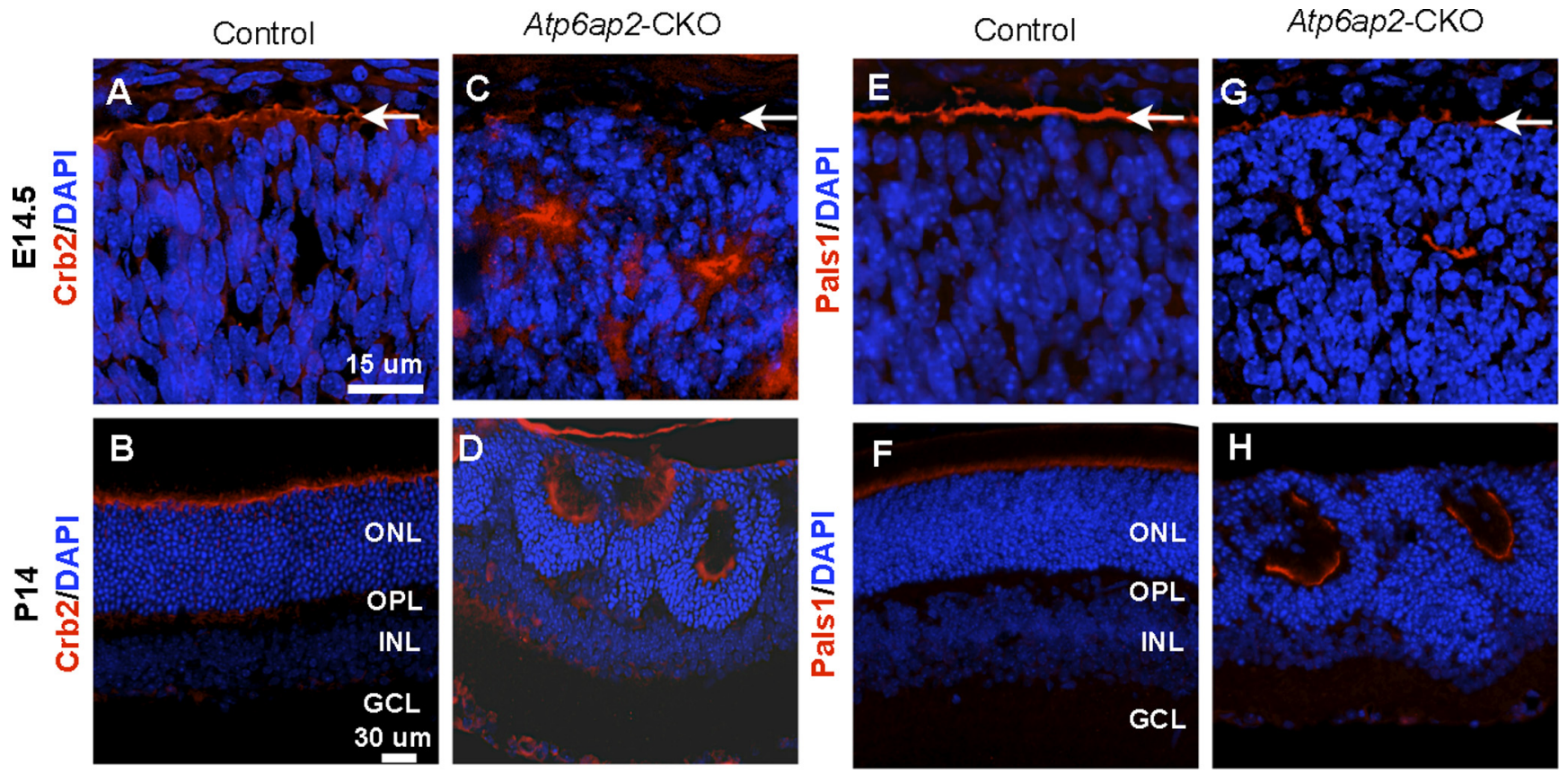

Figure 5. Loss of Atp6ap2 in photoreceptor cells led to mislocalization of cell polarity molecules related to the Crb-Pals1 complex. Sections of control $(\boldsymbol{A}, \boldsymbol{B}, \boldsymbol{E}, \boldsymbol{F})$ or $A \operatorname{tp} 6 a p 2$-CKO $(\boldsymbol{C}, \boldsymbol{D}, \boldsymbol{G}, \boldsymbol{H})$ retinas at E14.5 $(\boldsymbol{A}, \boldsymbol{C}, \boldsymbol{E}, \boldsymbol{G})$ and P14 (B, $\boldsymbol{D}, \boldsymbol{F}, \boldsymbol{H})$ were stained with antibodies (red) against $\mathrm{Crb2}(\boldsymbol{A}-\boldsymbol{D})$ and Pals1 $(\boldsymbol{E}-\boldsymbol{H})$. Nuclei were counterstained with DAPI (blue). Arrows indicate apical edge. Scale bars: $A, 15 \mu \mathrm{m} ; B, 30 \mu \mathrm{m}$.

2012). Crb2 (Fig. 5A-D) and Pals1 (Fig. 5E-H) signals in the Atp6ap2-CKO retinas were substantially mislocalized from the apical surface at E14.5 (Fig. 5A, $C, E, G$ ) and from photoreceptor cells at P14 (Fig. 5B,D,F,H). More importantly, however, Crb2 and Pals 1 mutant mice were reported to exhibit retinal phenotypes at E18.5 and E15.5, respectively (Cho et al., 2012; Alves et al., 2013), whereas the Atp6ap2-CKO retina exhibited morphological changes earlier at E14.5 (Fig. $2 B, E$ ). Combined with the lack of colocalization of Atp6ap2 with Crb2 and Pals1 (Fig. 4J$O)$, the Crb complex would not be the direct target of Atp6ap2 in retinal laminar formation.

Recent reports have shown that Atp6ap2 is essential for Wnt/ $\beta$-catenin signaling (Buechling et al., 2010; Cruciat et al., 2010) and that Atp6ap2 in Drosophila interacts with protocadherin Flamingo (Hermle et al., 2013). In the CKO retina at E14.5, adhesion [ $\beta$-catenin, N-cadherin, and zona occludens $(\mathrm{ZO})-1]$ and polarity (Par3, Par6, and aPKC $\lambda$ ) molecules were dispersed from the apical edge (Fig. $6 D-F, J-L$ ), all of which were located at the apical edge of control retinas (Fig. $6 A-C, G-I$ ). Immunoblot analysis showed that the expression levels of all these proteins were unaltered in the CKO retinas that exhibited significant reduction of Atp6ap2 protein as compared with controls (Fig. 6M). These data suggest that loss of Atp6ap2 in photoreceptor cells led to mislocalization of those cell adhesion and polarity molecules, whereas the amount of those proteins were unaffected.

\section{Loss of Atp6ap2 in photoreceptor cells disturbed retinal progenitor distribution}

Loss of cell adhesion and polarity molecules in the retina was reported to cause progenitor dispersions (Pujic and Malicki, 2001; Malicki et al., 2003; Masai et al., 2003; Koike et al., 2005). To examine whether the mislocalization of adhesion and polarity molecules in the Atp6ap2-CKO retina (Fig. 6) affects distribution of retinal progenitor cells, we performed immunostaining in the control and CKO retinas at E14.5 with the mitotic marker phos- phorylated ( $\mathrm{p}$ )-histone $\mathrm{H} 3$, which stains proliferating cells in late $G_{2}$ and $M$ phases (Prigent and Dimitrov, 2003). In the control retina, $\beta$-catenin and $\mathrm{N}$-cadherin were localized mainly at the apical surface with p-histone $\mathrm{H} 3$-positive progenitors in place (Fig. $7 A, B, A^{\prime}, B^{\prime}$ ). In contrast, the distribution of mitotic progenitor cells was markedly scattered in the Atp6ap2-CKO retina; however, $\beta$-catenin and $\mathrm{N}$-cadherin were localized around those dispersed progenitors (Fig. $7 C, D, C^{\prime}, D^{\prime}$ ). Additionally, we performed immunostaining with an antibody against $\alpha$-tubulin that labels mitotic spindles. Cell divisions in the Atp6ap2-CKO retina showed abnormal spindle orientation (Fig. $7 E, F, E^{\prime}, F^{\prime}$ ), which is similar with the phenotype of zebrafish mutants for heart and soul (has) encoding aPKC $\lambda$ (Horne-Badovinac et al., 2001). These results further confirm the disruption of retinal laminar structure in the Atp6ap2-CKO mice (Fig. 2) due to the mislocalization, but not the protein expression, of those molecules (Fig. 6).

\section{Interaction of Atp6ap2 with Par3}

Given that Atp6ap2 was colocalized with cell adhesion and polarity molecules (Fig. 4) and that the Atp6ap2-CKO mice exhibited disrupted retinal laminar structure (Fig. 2), we hypothesized that Atp6ap2 protein might interact with those molecules and thus participate in retinal lamination. To investigate protein interactions between Atp6ap2 and those adhesion and polarity molecules, we performed coimmunoprecipitation (IP) experiments using mouse retinal extracts as an input sample with antibodies against cell adhesion and polarity proteins, and immunoblot analysis using anti-Atp6ap2 antibody. The anti-Atp6ap2 antibody as a positive control for IP showed an immunoreactive band of the predicted size (Fig. 8A). Interestingly, the anti-Par3 antibody also demonstrated the precipitation of Atp6ap2 protein from the retina, whereas no other antibodies did (N-cadherin, $\beta$-catenin or aPKC $\lambda$; Fig. $8 A$; Par6, data not shown).

To investigate direct molecular interaction between ATP6AP2 and PAR3, we performed yeast two-hybrid analyses using 

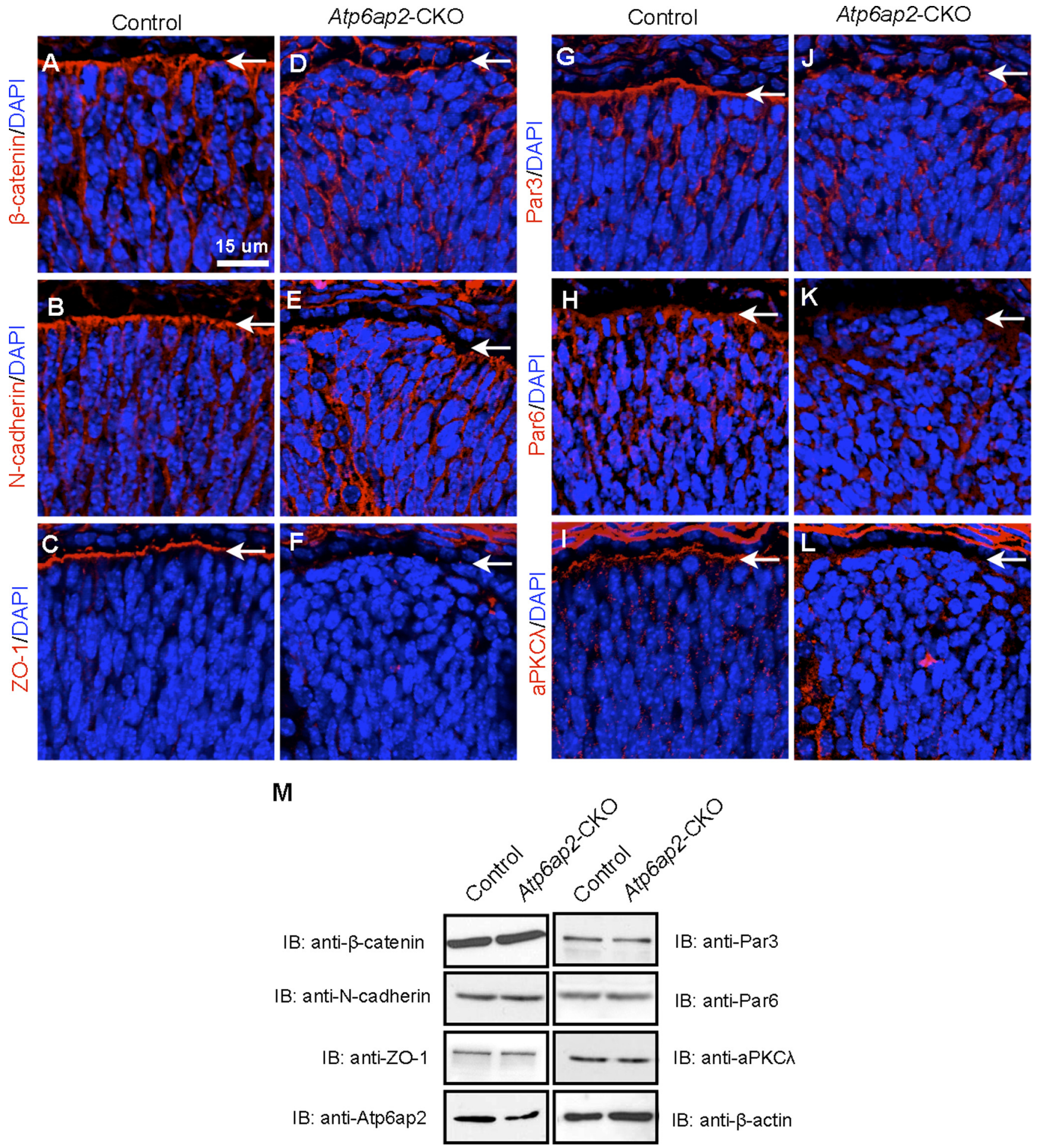

Figure 6. Loss of Atp6ap2 in photoreceptor cells led to mislocalization of cell adhesion and polarity molecules related to the Par-aPKC complex. Sections of control (A-C, G-I) or Atp6ap2-CKO $(\boldsymbol{D}-\boldsymbol{F}, \boldsymbol{J}-\boldsymbol{L})$ retinas at $\mathrm{E} 14.5$ were stained with individual antibodies (red) against $\beta$-catenin $(\boldsymbol{A}, \boldsymbol{D}), \mathrm{N}$-cadherin $(\boldsymbol{B}, \boldsymbol{E}), \mathbf{Z 0 - 1}(\boldsymbol{C}, \boldsymbol{F}), \operatorname{Par} 3(\mathbf{G}, \boldsymbol{J}), \operatorname{Par} 6(\boldsymbol{H}, \boldsymbol{K})$, and aPKC $\boldsymbol{\lambda}(\boldsymbol{I}, \boldsymbol{L})$. Nuclei were counterstained with DAPI (blue). Arrows indicate apical edge. Scale bar, $15 \mu \mathrm{m}$. M, Immunoblot analyses for $\beta$-catenin, $\mathrm{N}$-cadherin, Z0-1, Atp6ap2, Par3, Par6, aPKC $\lambda$, and $\beta$-actin proteins in P3 retinas.

ATP6AP2 and PAR3 subcloned alternately into either the bait (pGBKT7) or prey (pGADT7) vector. Yeast AH109 cells containing both pGBKT7-ATP6AP2 and pGADT7-PAR3 as well as both pGBKT7-PAR3 and pGADT7-ATP6AP2 grew well in nutrition selection plates (minus-TRP, -LEU, -HIS, and -ADE) with lacZ expression in blue, whereas those with empty bait or prey vector showed no growth (Fig. 8B).
To further validate the interaction between Atp6ap2 and Par3, IP experiments followed by immunoblot analysis were performed with transfected HEK293T cells using antibodies against Myc- or FLAG-tag. We subcloned human PAR3 and ATP6AP2 cDNAs into expression vectors containing Myc and FLAG, respectively, and cotransfected both of these constructs into HEK293T cells. IP with anti-Myc antibody from the cotrans- 

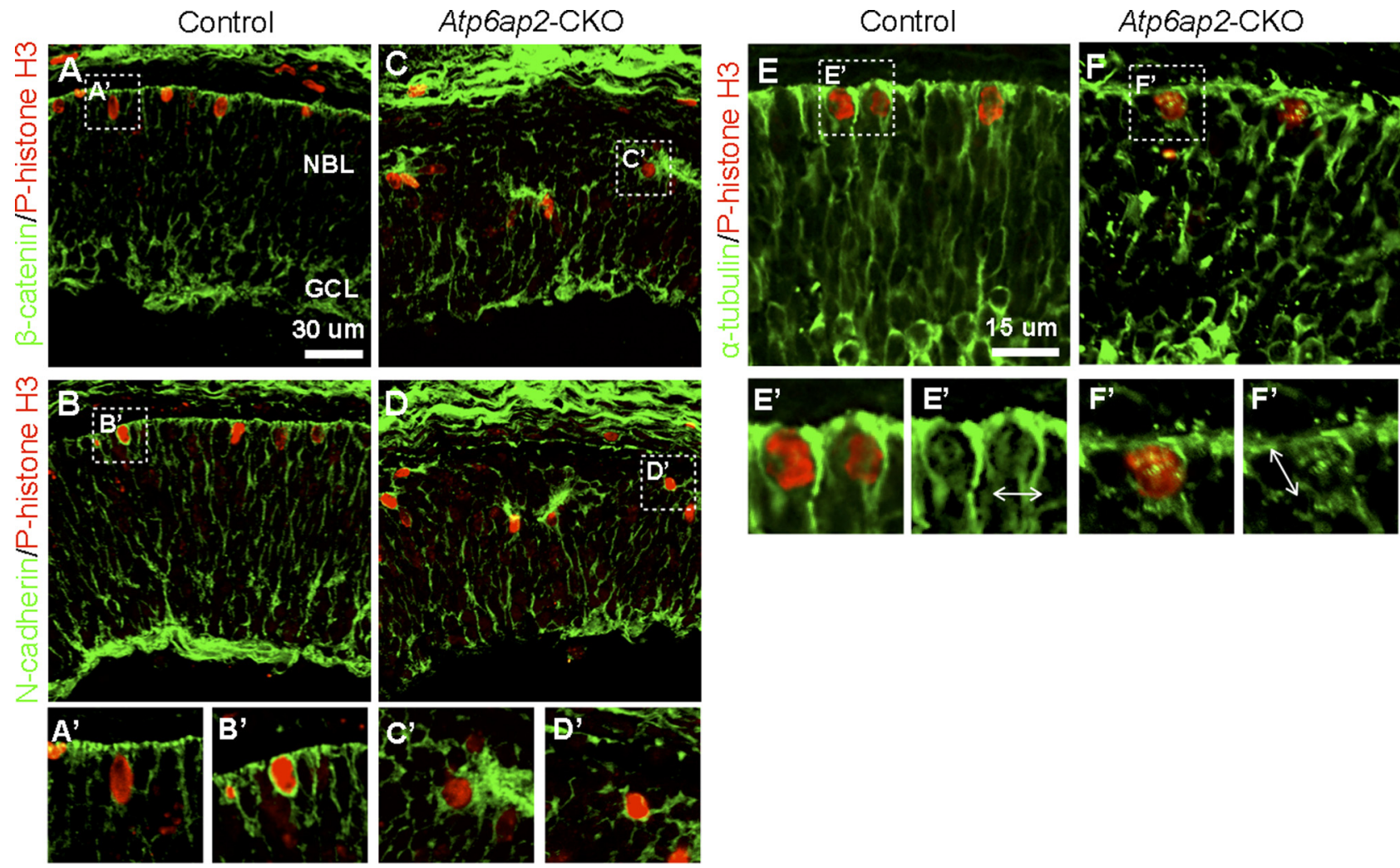

Figure 7. Loss of Atp6ap2 in photoreceptor cells disturbed retinal progenitor distribution. $\boldsymbol{A}, \boldsymbol{B}$, Double-labeling of $\beta$-catenin (green) and p-histone $\mathrm{H3}$ (progenitors, red). $\boldsymbol{C}, \boldsymbol{D}, \mathbf{D}$ ouble-labeling of N-cadherin (green) and p-histone H3 (red). $\boldsymbol{A}^{\prime}-\boldsymbol{D}^{\prime}$, Higher-magnification images of p-histone H3-positive cells. NBL, Neuroblastic layer; GCL, ganglion cell layer. Scale bar, $30 \mu \mathrm{m}$. $\boldsymbol{E}, \boldsymbol{F}$, Double-labeling of $\alpha$-tubulin (green) and p-histone H3 (red). $\boldsymbol{E}^{\prime}, \boldsymbol{F}^{\prime}$ Higher-magnification images. Double arrows show the orientation of mitotic spindles. Scale bar, $15 \mu \mathrm{m}$.

fected cell extracts demonstrated that PAR3 could pull down ATP6AP2 (Fig. 8D). Additionally, we generated three deletion mutants of ATP6AP2 (Fig. 8C) for IP experiments to address a key domain to interact with PAR3 protein. Intriguingly, deletion of the C-terminal domain together with the transmembrane (TM) domain (ATP6AP2- $\triangle \mathrm{C}$ ) or the N-terminal domain (ATP6AP2- $\Delta N$ ) lost interaction with PAR3, but addition of the TM domain to ATP6AP2- $\Delta$ C (ATP6AP2+TM) recovered interaction with PAR3 (Fig. 8D). Known-bait and known-prey experiments with these deletion mutants indicated their interactions with PAR3 except for ATP6AP2- $\Delta \mathrm{N}$ (Fig. $8 E$ ). These results suggest that the N-terminal domain in ATP6AP2 protein is a minimal region required for binding to PAR3 and that the TM domain is important for intracellular localization in mammalian cells.

\section{Intracellular localization of Atp6ap2-Par3 complex in the} developing retina

The endoplasmic reticulum (ER) and Golgi apparatus are essential for protein biosynthesis and modification, leading subsequently to intracellular distribution of functional molecules. Atp6ap2 was shown to have a predilection for the ER and Golgi network (Schefe et al., 2006). In concert with these findings, the requirement of the TM domain for ATP6AP2 binding to PAR3 (Fig. $8 D$ ) led us to hypothesize that those intracellular membranous organelles may harbor the Atp6ap2-Par3 complex. To clarify this, we performed immunofluorescence with antibodies against calreticulin (ER marker) and 58K Golgi protein (Golgi marker) in the WT mouse retina at E14.5. Calreticulin was ubiquitously distributed in retinal cells (Fig. $9 \mathrm{~A}$ ), whereas $58 \mathrm{~K}$ Golgi mainly localized in the apical surface (Fig. 9E). Importantly, those signals were colocalized with immunostaining for Atp6ap2 and Par3 (Fig. 9B-D,F-H). In contrast, signals of $\beta$-catenin exhibited substantially less frequent colocalization with calreticulin and $58 \mathrm{~K}$ Golgi protein, especially at the apical surface (Fig. $9 I-N)$. These results, in accordance with the finding that Par families are transported from the ER-Golgi network to the apical membrane via endocytic traffic (Shivas et al., 2010), suggest the critical role of Atp6ap2 in the apical distribution of Par3 and the biological significance of Atp6ap2 localization to the ER-Golgi system for developing cell polarity.

\section{Discussion}

Multiple studies have been conducted to show that Atp6ap2/ (P)RR plays significant roles in various pathological processes such as angiogenesis and inflammation (Kanda et al., 2012, 2013; Satofuka et al., 2012). The present study demonstrated several important data concerning the physiological role of Atp6ap2 in retinal development. First, Atp6ap2 was constitutively expressed in the mouse retina from embryo to adult (Fig. 1). Second, genetic ablation of the Atp6ap2 gene in photoreceptors led to disruption of retinal lamination and function (Fig. 2), but did not affect cell fate determination (Fig. 3). Third, Atp6ap2 was colocalized with cell adhesion and polarity proteins at the apical surface ( $\beta$-catenin, $\mathrm{N}$-cadherin, and Par3, but not Crb2 or Pals1; Fig. 4), and photoreceptor-specific deficiency in Atp6ap2 caused the mislocalization of these molecules (Figs. 5, 6) and retinal progenitor cells (Fig. 7). Importantly, IP experiments as well as yeast two-hybrid assays revealed molecular interaction of ATP6AP2 with PAR3 (Fig. 8). Finally, the ER-Golgi system was associated with Atp6ap2-Par3 colocalization in the developing retina (Fig. 9). These findings suggest that Atp6ap2 plays a critical role in the apical distribution of Par3 via the 
A

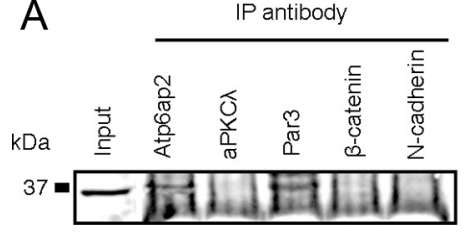

IB: anti-Atp6ap2

B
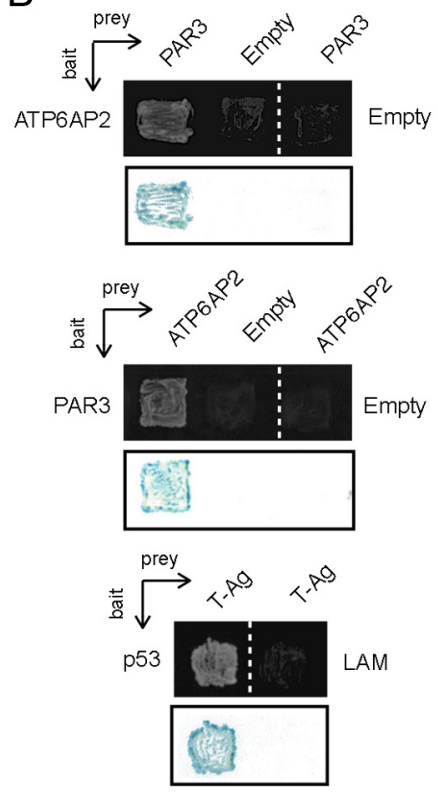

Positive Negative control control

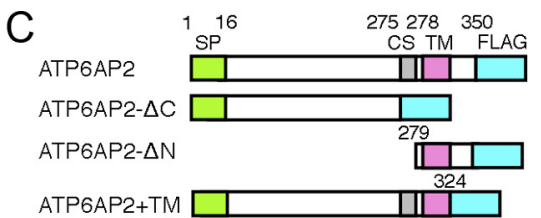

D

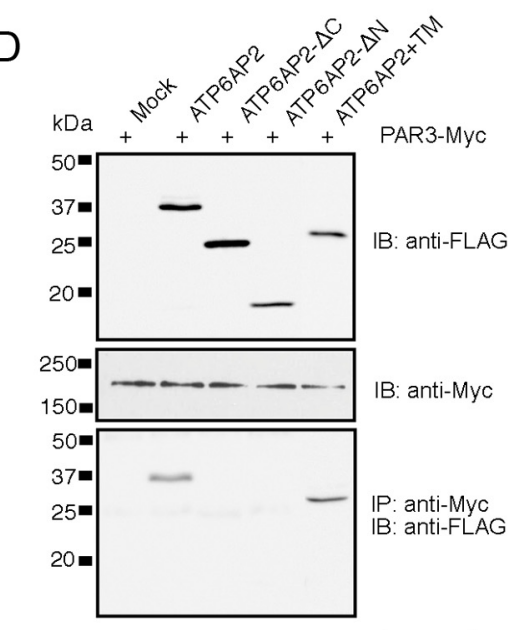

E

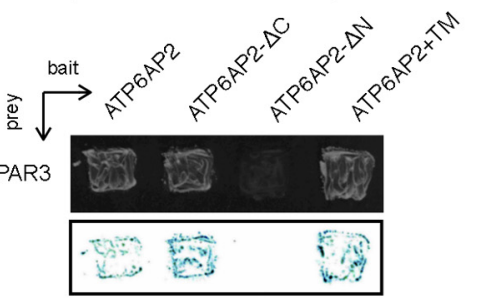

Figure 8. Interaction of Atp6ap2 with Par3.A, IP of WT retinal extracts using indicated antibodies were performed followed by SDS-PAGE and immunoblot analysis using anti-Atp6ap2 antibody. $\boldsymbol{B}$, Known-bait and known-prey yeast two-hybrid analyses. Top, Represents the growth of yeast transformed with ATP6AP2 (bait or prey) and PAR3 (prey or bait) constructs (growth assay). Interaction between p53 (bait) and T antigen (T-Ag; prey) was used as a positive control, while laminin (LAM; bait) and T-Ag association served as a negative control in this system. Bottom, Represents $\beta$-galactosidase color (blue) tests for the growth assay shown in the top. C, Schematic representation of ATP6AP2 constructs used. SP, Signal peptide; CS, furin cleavage site; TM, transmembrane domain. D, Cotransfection and IP. FLAG-tagged ATP6AP2 expression plasmids were cotransfected into HEK293T cells with Myc-tagged PAR3 expression constructs. IP with anti-Myc antibody followed by detection with anti-FLAG antibody. $\boldsymbol{E}$, Known-bait and known-prey yeast two-hybrid analyses. Top, Represents the growth of yeast transformed with the ATP6AP2 deletion mutants (bait) and PAR3 (prey).

ER-Golgi network, leading to the establishment of retinal lamination during physiological development.

The mammalian retina contains a highly organized laminar structure that captures, integrates, and transmits visual information to the brain for further processing (Masland, 2001; Swaroop et al., 2010). Several studies with mice and zebrafish have reported key proteins for retinal lamination including cell adhesion molecules, such as $\beta$-catenin and N-cadherin (Erdmann et al., 2003; Malicki et al., 2003; Masai et al., 2003; Fu et al., 2006) and cell polarity molecules, such as nagie oko and aPKC (Horne-Badovinac et al., 2001; Wei and Malicki, 2002; Wei et al., 2004; Koike et al., 2005). The Par family proteins are involved in establishing cell polarity, mediating cellular asymmetry through formation and distribution of molecular complexes (Guo and Kemphues, 1996). Par3 forms a complex with aPKC $\lambda$ and Par6 (i.e., the Par-aPKC system), which selectively localized to cellular junctions, such as $\mathrm{N}$-cadherin, and contributes to the regulation of polarity in a variety of cells (Izumi et al., 1998; Suzuki and Ohno, 2006; Insolera et al., 2011). Dysfunction of Par3 disturbed retinal lamination in the zebrafish eye (Wei et al., 2004). In this study, deletion of Atp6ap 2 in photoreceptors exhibited laminar disorganization in the photoreceptor layer (Fig. 2), which is

similar in retinal phenotype in the abovementioned vertebrates deficient in any of those cell polarity and adhesion molecules, and Atp6ap2 protein interacted and colocalized with Par3 in the ER-Golgi system (Figs. 4, 8, 9). In accordance with those previous reports on genetically modified animals, our present findings suggest that the mislocalization of Par3 protein at the apical edge was responsible for abnormal retinal lamination in Atp6ap2-CKO mice.

When functioning as $(\mathrm{P}) \mathrm{RR}$ to bind its ligand prorenin, Atp6ap2 is known to have its $\mathrm{N}$-terminal domain targeted to the extracellular space (i.e., to the ER lumen during synthesis) or released in a truncated form as soluble (P)RR (Kanda et al., 2012). On the other hand, singlepass molecules with their C-terminal domains targeted to the ER lumen are topologically classified into type II transmembrane proteins. Indeed, as an accessory subunit for v-ATPase for urinary acidification, Atp6ap2 (C-terminal region) was shown to be detectable within the Golgi apparatus and at the luminal surface of intercalated cells in the kidney collecting duct (Advani et al., 2009). Therefore, it is reasonable to speculate that the direction of Atp6ap2 to penetrate the lipid membrane may differ depending on its multiple functions. The current data on Atp6ap2 interaction with Par3 (Figs. 8, 9) suggest that Atp6ap2 had its $\mathrm{N}$-terminal domain targeted to the cytoplasm harboring Par3.

Atp6ap2/(P)RR was initially identified as an adaptor protein for the proton pump v-ATPase complex that is a key regulator of acidification of endosomes, lysosomes, and secretory vesicles (Nishi and Forgac, 2002). Mutations in the v-ATPase complex (Atp6ap1, Atp6v0c, Atp6v0d1, Atp6v1e1, Atp6v1f, or Atp6v1h) in zebrafish demonstrated numerous vacuoles within retinal pigment epithelium together with abnormal outer segment morphology; however, retinal lamination appeared unaffected in all the mutants for v-ATPase subunits except Atp6r0c (Nuckels et al., 2009). Similarly, Atp6v0a3 knock-out mice exhibited no obvious change in retinal laminated structure although optic nerve compression developed with retinal degeneration in adults (Kawamura et al., 2010). These results suggest that the disruption of retinal lamination in our Atp6ap2-CKO mice did not depend on the v-ATPase function of Atp6ap2.

In conclusion, our present findings unravel the novel function of Atp6ap2/(P)RR that binds to Par3 as a cell polarity determinant required for retinal laminar organization during physiological development. Atp6ap2/(P)RR has so far been shown to be involved in multiple physiological and pathological events depending on its v-ATPase function and tissue RAS activation. We propose that this cellular activity associated with the Par-aPKC system, in addition to the v-ATPase function and tissue RAS activation, is the third biological role of Atp6ap2/(P)RR. 

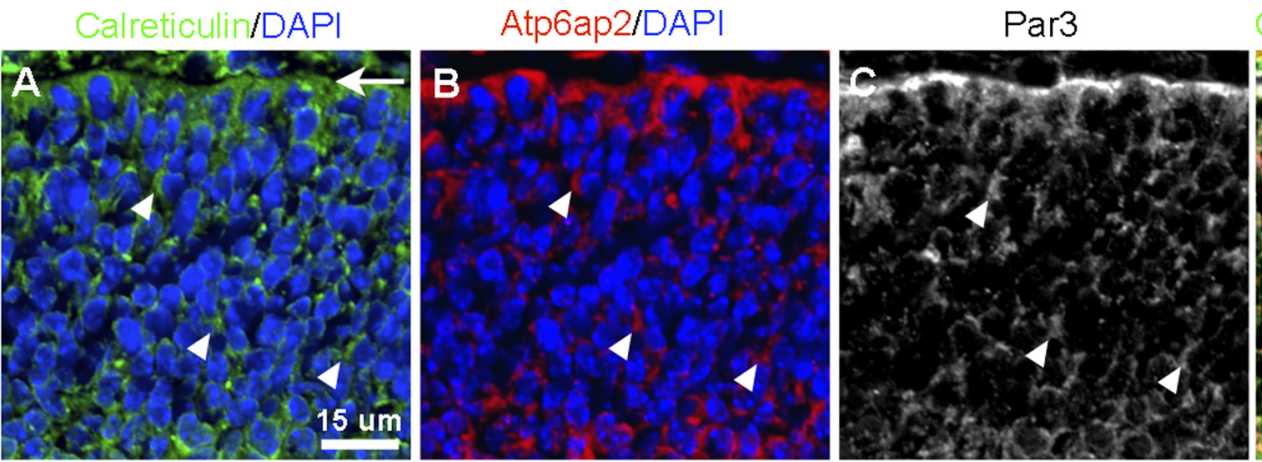

Calreticulin/Atp6ap2/Par3
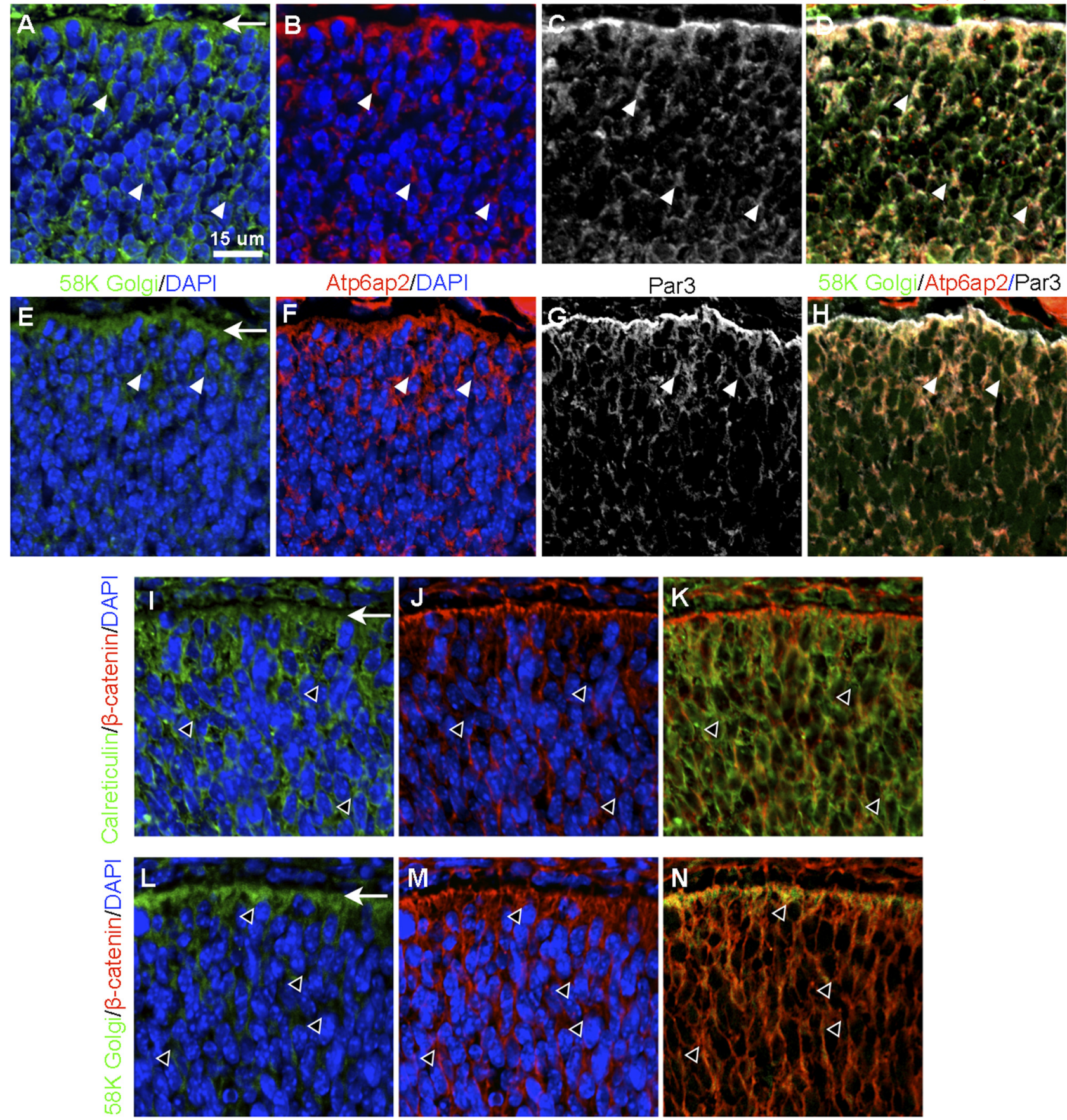

Figure 9. Intracellular localization of Atp6ap2-Par3 complex in the developing retina. A-D, Immunolabeling for calreticulin (ER, green), Atp6ap2 (red), Par3 (gray), and DAPI (blue) on WT retinas at E14.5. E-H, Immunolabeling for 58K Golgi protein (Golgi, green), Atp6ap2 (red), Par3 (gray), and DAPI (blue). Arrowheads and arrows indicate Atp6ap2-Par3 colocalization with the ER-Golgi network and the apical edge of the retina, respectively. Immunolabeling for calreticulin (green), $\beta$-catenin (red) and DAPI (blue; $\boldsymbol{I}-\boldsymbol{K}$ ), and 58K Golgi protein (green), $\beta$-catenin (red), and DAPI (blue; $\boldsymbol{L}-\boldsymbol{N}$ ) on WT retinas at E14.5. Open arrowheads and arrows indicate separate localization of $\beta$-catenin from the ER-Golgi network and the apical edge of the retina, respectively. Scale bar, $15 \mu \mathrm{m}$.

\section{References}

Adams DS, Robinson KR, Fukumoto T, Yuan S, Albertson RC, Yelick P, Kuo L, McSweeney M, Levin M (2006) Early, H+-V-ATPase-dependent proton flux is necessary for consistent left-right patterning of nonmammalian vertebrates. Development 133:1657-1671. CrossRef Medline Advani A, Kelly DJ, Cox AJ, White KE, Advani SL, Thai K, Connelly KA, Yuen D, Trogadis J, Herzenberg AM, Kuliszewski MA, Leong-Poi H, Gilbert RE (2009) The (pro)renin receptor: site-specific and functional linkage to the vacuolar H+-ATPase in the kidney. Hypertension 54:261-269. CrossRef Medline

Alves CH, Sanz AS, Park B, Pellissier LP, Tanimoto N, Beck SC, Huber G, Murtaza M, Richard F, Sridevi Gurubaran I, Garcia Garrido M, Levelt CN, Rashbass P, Le Bivic A, Seeliger MW, Wijnholds J (2013) Loss of $\mathrm{CRB} 2$ in the mouse retina mimics human retinitis pigmentosa due to mutations in the CRB1 gene. Hum Mol Genet 22:35-50. CrossRef Medline

Buechling T, Bartscherer K, Ohkawara B, Chaudhary V, Spirohn K, Niehrs C, Boutros M (2010) Wnt/Frizzled signaling requires dPRR, the Drosophila homolog of the prorenin receptor. Curr Biol 20:1263-1268. CrossRef Medline 
Bulgakova NA, Knust E (2009) The Crumbs complex: from epithelial-cell polarity to retinal degeneration. J Cell Sci 122:2587-2596. CrossRef Medline

Cho SH, Kim JY, Simons DL, Song JY, Le JH, Swindell EC, Jamrich M, Wu SM, Kim S (2012) Genetic ablation of Pals1 in retinal progenitor cells models the retinal pathology of Leber congenital amaurosis. Hum Mol Genet 21:2663-2676. CrossRef Medline

Cruciat CM, Ohkawara B, Acebron SP, Karaulanov E, Reinhard C, Ingelfinger D, Boutros M, Niehrs C (2010) Requirement of prorenin receptor and vacuolar $\mathrm{H}+$-ATPase-mediated acidification for Wnt signaling. Science 327:459-463. CrossRef Medline

Erdmann B, Kirsch FP, Rathjen FG, Moré MI (2003) N-cadherin is essential for retinal lamination in the zebrafish. Dev Dyn 226:570-577. CrossRef Medline

Fu X, Sun H, Klein WH, Mu X (2006) Beta-catenin is essential for lamination but not neurogenesis in mouse retinal development. Dev Biol 299: 424-437. CrossRef Medline

Guo S, Kemphues KJ (1996) Molecular genetics of asymmetric cleavage in the early Caenorhabditis elegans embryo. Curr Opin Genet Dev 6:408415. CrossRef Medline

Hermle T, Saltukoglu D, Grünewald J, Walz G, Simons M (2010) Regulation of Frizzled-dependent planar polarity signaling by a V-ATPase subunit. Curr Biol 20:1269-1276. CrossRef Medline

Hermle T, Guida MC, Beck S, Helmstädter S, Simons M (2013) Drosophila ATP6AP2/VhaPRR functions both as a novel planar cell polarity core protein and a regulator of endosomal trafficking. EMBO J 32:245-259. CrossRef Medline

Horne-Badovinac S, Lin D, Waldron S, Schwarz M, Mbamalu G, Pawson T, Jan Y, Stainier DY, Abdelilah-Seyfried S (2001) Positional cloning of heart and soul reveals multiple roles for PKC lambda in zebrafish organogenesis. Curr Biol 11:1492-1502. CrossRef Medline

Insolera R, Chen S, Shi SH (2011) Par proteins and neuronal polarity. Dev Neurobiol 71:483-494. CrossRef Medline

Izumi Y, Hirose T, Tamai Y, Hirai S, Nagashima Y, Fujimoto T, Tabuse Y, Kemphues KJ, Ohno S (1998) An atypical PKC directly associates and colocalizes at the epithelial tight junction with ASIP, a mammalian homologue of Caenorhabditis elegans polarity protein PAR-3. J Cell Biol 143:95-106. CrossRef Medline

Kanda A, Noda K, Saito W, Ishida S (2012) (Pro)renin receptor is associated with angiogenic activity in proliferative diabetic retinopathy. Diabetologia 55:3104-3113. CrossRef Medline

Kanda A, Noda K, Saito W, Ishida S (2013) Vitreous renin activity correlates with vascular endothelial growth factor in proliferative diabetic retinopathy. Br J Ophthalmol 97:666-668. CrossRef Medline

Kawamura N, Tabata H, Sun-Wada GH, Wada Y (2010) Optic nerve compression and retinal degeneration in Tcirgl mutant mice lacking the vacuolar-type H-ATPase a3 subunit. PloS one 5:e12086. CrossRef Medline

Kinouchi K, Ichihara A, Sano M, Sun-Wada GH, Wada Y, Kurauchi-Mito A, Bokuda K, Narita T, Oshima Y, Sakoda M, Tamai Y, Sato H, Fukuda K, Itoh H (2010) The (pro)renin receptor/ATP6AP2 is essential for vacuolar H+-ATPase assembly in murine cardiomyocytes. Circ Res 107:30-34. CrossRef Medline

Koike C, Nishida A, Akimoto K, Nakaya MA, Noda T, Ohno S, Furukawa T (2005) Function of atypical protein kinase C lambda in differentiating photoreceptors is required for proper lamination of mouse retina. J Neurosci 25:10290-10298. CrossRef Medline

Ludwig J, Kerscher S, Brandt U, Pfeiffer K, Getlawi F, Apps DK, Schägger H (1998) Identification and characterization of a novel 9.2-kDa membrane sector-associated protein of vacuolar proton-ATPase from chromaffin granules. J Biol Chem 273:10939-10947. CrossRef Medline

Malicki J, Jo H, Pujic Z (2003) Zebrafish N-cadherin, encoded by the glass onion locus, plays an essential role in retinal patterning. Dev Biol 259:95108. CrossRef Medline

Masai I, Lele Z, Yamaguchi M, Komori A, Nakata A, Nishiwaki Y, Wada H,
Tanaka H, Nojima Y, Hammerschmidt M, Wilson SW, Okamoto H (2003) N-cadherin mediates retinal lamination, maintenance of forebrain compartments and patterning of retinal neurites. Development 130: 2479-2494. CrossRef Medline

Masland RH (2001) The fundamental plan of the retina. Nat Neurosci 4:877-886. CrossRef Medline

Nguyen G, Delarue F, Burcklé C, Bouzhir L, Giller T, Sraer JD (2002) Pivotal role of the renin/prorenin receptor in angiotensin II production and cellular responses to renin. J Clin Invest 109:1417-1427. CrossRef Medline

Nishi T, Forgac M (2002) The vacuolar (H+)-ATPases: nature's most versatile proton pumps. Nat Rev Mol Cell Biol 3:94-103. CrossRef Medline

Nishida A, Furukawa A, Koike C, Tano Y, Aizawa S, Matsuo I, Furukawa T (2003) Otx2 homeobox gene controls retinal photoreceptor cell fate and pineal gland development. Nat Neurosci 6:1255-1263. CrossRef Medline

Nuckels RJ, Ng A, Darland T, Gross JM (2009) The vacuolar-ATPase complex regulates retinoblast proliferation and survival, photoreceptor morphogenesis, and pigmentation in the zebrafish eye. CrossRef Invest Ophthalmol Vis Sci 50:893-905. Medline

Omori Y, Malicki J (2006) Oko meduzy and related crumbs genes are determinants of apical cell features in the vertebrate embryo. Curr Biol 16:945957. CrossRef Medline

Oshima Y, Kinouchi K, Ichihara A, Sakoda M, Kurauchi-Mito A, Bokuda K, Narita T, Kurosawa H, Sun-Wada GH, Wada Y, Yamada T, Takemoto M, Saleem MA, Quaggin SE, Itoh H (2011) Prorenin receptor is essential for normal podocyte structure and function. J Am Soc Nephrol 22:22032212. CrossRef Medline

Prigent C, Dimitrov S (2003) Phosphorylation of serine 10 in histone H3, what for? J Cell Sci 116:3677-3685. CrossRef Medline

Pujic Z, Malicki J (2001) Mutation of the zebrafish glass onion locus causes early cell-nonautonomous loss of neuroepithelial integrity followed by severe neuronal patterning defects in the retina. Dev Biol 234:454-469. CrossRef Medline

Riediger F, Quack I, Qadri F, Hartleben B, Park JK, Potthoff SA, Sohn D, Sihn G, Rousselle A, Fokuhl V, Maschke U, Purfürst B, Schneider W, Rump LC, Luft FC, Dechend R, Bader M, Huber TB, Nguyen G, Muller DN (2011) Prorenin receptor is essential for podocyte autophagy and survival. J Am Soc Nephrol 22:2193-2202. CrossRef Medline

Satofuka S, Kanda A, Ishida S (2012) Receptor-associated prorenin system in the pathogenesis of retinal diseases. Front Biosci 4:1449-1460. CrossRef Medline

Schefe JH, Menk M, Reinemund J, Effertz K, Hobbs RM, Pandolfi PP, Ruiz P, Unger T, Funke-Kaiser H (2006) A novel signal transduction cascade involving direct physical interaction of the renin/prorenin receptor with the transcription factor promyelocytic zinc finger protein. Circ Res 99: 1355-1366. CrossRef Medline

Shivas JM, Morrison HA, Bilder D, Skop AR (2010) Polarity and endocytosis: reciprocal regulation. Trends Cell Biol 20:445-452. CrossRef Medline

Suzuki A, Ohno S (2006) The PAR-aPKC system: lessons in polarity. J Cell Sci 119:979-987. CrossRef Medline

Swaroop A, Kim D, Forrest D (2010) Transcriptional regulation of photoreceptor development and homeostasis in the mammalian retina. Nat Rev Neurosci 11:563-576. CrossRef Medline

Wei X, Malicki J (2002) nagie oko, encoding a MAGUK-family protein, is essential for cellular patterning of the retina. Nat Genet 31:150-157. CrossRef Medline

Wei X, Cheng Y, Luo Y, Shi X, Nelson S, Hyde DR (2004) The zebrafish Pard3 ortholog is required for separation of the eye fields and retinal lamination. Dev Biol 269:286-301. CrossRef Medline

Yuki K, Ozawa Y, Yoshida T, Kurihara T, Hirasawa M, Ozeki N, Shiba D, Noda K, Ishida S, Tsubota K (2011) Retinal ganglion cell loss in superoxide dismutase 1 deficiency. Invest Ophthalmol Vis Sci 52:4143-4150. CrossRef Medline

Zou J, Wang X, Wei X (2012) Crb apical polarity proteins maintain zebrafish retinal cone mosaics via intercellular binding of their extracellular domains. Dev Cell 22:1261-1274. CrossRef Medline 